\title{
Protective effect of luteolin on the transgenic Drosophila model of Parkinson's disease
}

\author{
Yasir Hasan Siddique ${ }^{1}$, Smita Jyoti', Falaq Naz ${ }^{1}$, Rahul ${ }^{1}$ \\ ${ }^{1}$ Drosophila Transgenic Laboratory, Section of Genetics, Department of Zoology, Aligarh Muslim University, \\ Aligarh, U.P. India
}

\begin{abstract}
In the present study we have studied the effect of $25,50,75$ and $100 \mu \mathrm{M}$ of luteolin on the transgenic Drosophila expressing human alpha synuclein. The doses of luteolin were established in diet and the PD flies were allowed to feed on it for 24 days. After 24 days of exposure the flies were assayed for climbing assay, oxidative stress markers, caspase- $3 \& 9$ activity and dopamine content. The immunohistochemistry was also performed on the brain sections for the activity of tyrosine hydroxylase. The exposure of luteolin showed a dose dependent delay in the loss of climbing ability and activity, reduction in oxidative stress markers, caspase-3\&9 activities and results in an increase in the dopamine content. The results obtained for the immunohistochemistry also supports the protective role of luteolin against the damage of the dopaminergic neurons.
\end{abstract}

Keywords: Luteolin. Parkinson's disease. Drosophila. Oxidative stress.

\section{INTRODUCTION}

Parkinson's disease (PD) is a common progressive neurodegenerative disorder characterized by the loss of dopaminergic neurons due to the over expression of alpha synuclein and formation of the Lewy bodies (ShaltielKaryo et al., 2012). The loss of the dopaminergic neurons has been implicated in causing severe motor symptoms (Jenner, Olanow, 2006). Lewy bodies are spherical protein inclusions found in the cytoplasm of surviving neurons and consisted of a dense core surrounded by a halo of radiating fibrils of $\alpha$-synuclein (Meng et al., 2010). The formation of Lewy bodies has been linked with the production of reactive oxygen species (ROS) leading to a state of oxidative stress producing superoxide radical anions, hydrogen peroxide and hydroxyl radicals (Thomas, Beal, 2007; Cookson, 2005; Auluck et al., 2002). There are enough evidences showing an increase of oxidative stress during the progression of neurodegenerative diseases such as Parkinson's and Alzheimer's disease (Marsh, Thompson, 2006; Filomeni et al., 2012; Behl, Holsboer, 1998).

\footnotetext{
*Correspondence: Y. H. Siddique. Drosophila Transgenic Laboratory, Section of Genetics, Department of Zoology, Aligarh Muslim University, Aligarh. Telephone: 0571-2700920-3447.E-mail: yasir_hasansiddique@rediffmail.com
}

Oxidative stress has also been implicated in neuronal loss associated with cognitive decline. The potential role of ROS and reactive nitrogen species (RNS) in the pathophysiology of neurodegenerative disorder is relevant as nitric oxide (NO) and superoxide $\left(\mathrm{O}_{2}^{\circ}\right)$ may be generated in the brain and their formation is often co-localised in specific neurons (Youdim et al., 2002). Recently, there has been a considerable attention for establishing a therapeutic and dietary strategy to combat oxidative stress during the progression of neurodegenerative diseases. In this context a number of dietary antioxidants especially flavonoids have been screened for their biological actions (Singh, Rajini, 2004; Seidl et al., 2014). As there is no preventive therapy for the neurodegenerative diseases till date, hence any agent that can slow /or prevent aggregation and fibrillation of $\alpha$-synuclein or reduced the oxidative stress could act as a possible therapeutic agent. Luteolin is a polyphenolic compound found in celery, green pepper, perilla leaf and camomile tea (Chen et al., 2008). It has been reported to possess anti-mutagenic, anti-tumorigenic, antioxidant and anti-inflammatory properties but the investigations exploring its nature on the neurodegenerative disorders are warranted. The present study deals with the effect of luteolin on the PD model flies expressing human alpha synuclein in the brain. 


\section{MATERIAL AND METHODS}

\section{Drosophila stocks}

Transgenic fly lines that express wild-type human synuclein $(h-\alpha S)$ under UAS control in neurons "[w[*];P $\{\mathrm{w}[+\mathrm{mC}]=\mathrm{UAS}-\mathrm{Hsap} / \mathrm{SNCA} . \mathrm{F}\} "$ "5B and GAL4 "w[*];P $\{\mathrm{w}[+\mathrm{mC}]=\mathrm{GAL} 4-$ elavL $\}$ "3] were obtained from Bloomington Drosophila Stock Centre (Indiana University, Bloomington, IN). When the males of UAS (Upstream Activation Sequence)-Hsap/SNCA.F strains are crossed with the females of GAL4-elav. L (vice-versa), the progeny will express human $\alpha \mathrm{S}$ in the neurons (Feany, Bender, 2000).

\section{Drosophila culture and crosses}

The flies were cultured on standard Drosophila food containing agar, corn meal, sugar and yeast at $25^{\circ} \mathrm{C}$ $(24 \pm 1)$ (Siddique et al., 2014). Crosses were set up as described in our earlier published work (Siddique et al., 2012). The PD flies were allowed to feed separately on different doses of luteolin (Sigma, USA) mixed in the diet. Luteolin was added in the diet at final concentration of 25 , 50,75 and $100 \mu \mathrm{M}$. The PD flies were also exposed to $10^{-3}$ M of L-dopamine. The UASHsap/ SNC.F act as a control. The control flies were allowed separately to feed on the selected doses of luteolin. Fly heads from each group were isolated (50 heads/group; five replicates/group) and the homogenate was prepared in $0.1 \mathrm{M}$ phosphate buffer for the biochemical parameters.

\section{Antioxidative assays}

Two assays were used for estimating the antioxidative potential of luteolin for the doses selected in our study

\section{Superoxide anion scavenging assay}

The inhibition of Nitroblue tetrazolium (NBT) reduction by phenazine methosulphate (PMS) generated $\mathrm{O}_{2}{ }^{-}$was used to determine the superoxide anion scavenging activity of the luteolin (Sghaier et al., 2011) The reaction mixture consist of $75 \mu \mathrm{L}$ of each concentration of luteolin, $750 \mu \mathrm{L}$ of Tris $\mathrm{HCl}(100 \mathrm{mM}$; $\mathrm{pH} 7.4) ; 187 \mu \mathrm{L}$ of NBT $(300 \mu \mathrm{M}), 187 \mu \mathrm{L}$ of NADH $(936 \mu \mathrm{M})$. The reaction was initiated by adding phenazine methosulphate (PMS) $(120 \mu \mathrm{M})$. The reaction mixture was incubated at $25^{\circ} \mathrm{C}$ for $5 \mathrm{~min}$ and the OD was read at $560 \mathrm{~nm}$ and the degree of scavenging was calculated by the following equation:
Scavenging $(\%)=\left[\frac{\text { OD control }- \text { OD sample }}{\text { OD control }}\right] \times 100$

\section{Diphenyl-picrylhydrazyl (DPPH) free radical scavenging}

For estimating free radical scavenging potential of the luteolin DPPH method as described by Wongsawatkul et al. (2008) was used in the present study. When DPPH (a stable purple color) react with an antioxidant, it is reduced to yield a light yellow coloured diphenyl picrylhydrazine. Color change was spectrophotometrically measured. The reaction mixture consisting of $500 \mu \mathrm{L}$ of luteolin and $250 \mu \mathrm{L}$ of DPPH $(0.3 \mathrm{mM})$. The reaction mixture was shaken vigorously and allowed to stand at room temperature in the dark for $25 \mathrm{~min}$. The OD was read at $518 \mathrm{~nm}$ and the radical scavenging activity was calculated by the following equation:

$$
\begin{gathered}
\% \text { Radical scavenging }=(1-\text { Absorbance of sample } / \\
\text { Absorbance of control }) \times 100
\end{gathered}
$$

\section{Drosophila climbing assay}

The climbing assay was performed as described by Pendleton et al. (2002). Ten flies were placed in an empty glass vial $(10.5 \mathrm{~cm} \times 2.5 \mathrm{~cm})$. A horizontal line was drawn $8 \mathrm{~cm}$ above the bottom of the vial. After the flies had acclimated for $10 \mathrm{~min}$ at room temperature, both controls and treated groups were assayed at random to a total of 10 trails for each. The mean values were calculated and then averaged, and a group mean and standard error were obtained. All behavioral studies were performed at $25^{\circ} \mathrm{C}$ under standard lighting conditions.

\section{Drosophila activity pattern}

From the 12th day the activity of flies (males) in all treated groups were analyzed by using Drosophila Activity Monitor (TriTek, USA). The activity was recorded every hour for a total of $287 \mathrm{~h}$ and the data was analyzed by Actogram J software. The results were presented as chisquare periodogram (Rasato, Kyriacou, 2006).

\section{Estimation of glutathione (GSH) content}

The GSH content was estimated colorimetrically using Ellman's reagent (DTNB) according to the procedure described by Jollow et al. (1974). The supernatant was precipitated with $4 \%$ sulphosalicyclic acid in the ratio 
of $1: 1$. The samples were kept at $4{ }^{\circ} \mathrm{C}$ for $1 \mathrm{hr}$ and then subjected to centrifugation at $4200 \mathrm{~g}$ for $10 \mathrm{~min}$ at $4{ }^{\circ} \mathrm{C}$. The assay mixture consisted of $550 \mu \mathrm{L}$ of $0.1 \mathrm{M}$ phosphate buffer, $100 \mu \mathrm{L}$ of supernatant and $100 \mu \mathrm{L}$ of DTNB. The OD was read at $412 \mathrm{~nm}$ and the results were expressed as $\mu$ moles of GSH/gram tissue.

\section{Estimation of glutathione-S-transferase (GST) activity}

The GST activity was determined by the method of Habig et al. (1974). The reaction mixture consisted of $500 \mu \mathrm{L}$ of $0.1 \mathrm{M}$ phosphate buffer, $150 \mu \mathrm{L}$ of $10 \mathrm{mM}$ $\mathrm{CDNB}, 200 \mu \mathrm{L}$ of $10 \mathrm{mM}$ reduced glutathione and $50 \mu \mathrm{L}$ of supernatant. The OD was taken at $340 \mathrm{~nm}$ and the enzyme activity was expressed as $\mu$ moles of CDNB conjugates/min/mg protein.

\section{Lipid peroxidation assay (LPO)}

LPO was measured according to the method described by Ohkawa, Nobuko, Yagi (1978). The reaction mixture consisted of $5 \mu \mathrm{L}$ of $10 \mathrm{mM}$ butyl-hydroxytoluene (BHT), $200 \mu \mathrm{L}$ of $0.67 \%$ thiobarbituric acid, $600 \mu \mathrm{L}$ of $1 \%$ O-phosphoric acid, $105 \mu \mathrm{L}$ of distilled water and $90 \mu \mathrm{L}$ of supernatant. The resultant mixture was incubated at $90{ }^{\circ} \mathrm{C}$ for $45 \mathrm{~min}$ and the OD was measured at $535 \mathrm{~nm}$. The results were expressed as $\mu \mathrm{mol}$ of TBARS formed $/ \mathrm{h} / \mathrm{g}$ tissue.

\section{Estimation of Protein Carbonyl content (PCC)}

The PCC was estimated according to the protocol described by Hawkins, Morgan, Davies (2009). The brain homogenate was diluted to a protein concentration of approx $1 \mathrm{mg} / \mathrm{mL}$. About $250 \mu \mathrm{L}$ of each diluted homogenate was taken in eppendorf centrifuge tubes separately. To it $250 \mu \mathrm{L}$ of $10 \mathrm{mM} \mathrm{2,4-dinitrophenyl}$ hydrazine (dissolved in $2.5 \mathrm{M} \mathrm{HCl}$ ) was added, vortexed and kept in dark for $20 \mathrm{~min}$. About $125 \mu \mathrm{L}$ of $50 \%(\mathrm{w} / \mathrm{v})$ trichloroacetic acid (TCA) was added, mixed thoroughly and incubated at $-20^{\circ} \mathrm{C}$ for $15 \mathrm{~min}$. The tubes were then centrifuged at $4{ }^{\circ} \mathrm{C}$ for $10 \mathrm{~min}$ at $8200 \mathrm{~g}$. The supernatant was discarded and the pellet obtained was washed twice by ice cold ethanol: ethyl acetate (1:1). Finally, the pellets were re-dissolved in $1 \mathrm{ml}$ of $6 \mathrm{M}$ guanidine hydrochloride and the absorbance was read at $370 \mathrm{~nm}$.

\section{Assay for caspase-3 (Drice) and caspase-9 (Dronc) activities}

For estimating the activities of caspase 3 and 9 the assay was performed according to the manufacturer protocol with some modification (Bio-Vision, CA, USA). The assay was based on spectrophotometric detection of the chromophore p-nitroanilide (pNA) obtained after specific action of caspase- 3 and caspase- 9 on tetrapeptide substrates, DEVD-pNA and IETD-pNA, respectively. The assay mixture consisted of $50 \mu \mathrm{L}$ of fly head homogenate from each group and $50 \mu \mathrm{L}$ of chilled cell lysis buffer incubated on ice for $10 \mathrm{~min}$. After incubation, $50 \mu \mathrm{L}$ of two times reaction buffer (containing $10 \mathrm{mM}$ DTT) with $200 \mu \mathrm{M}$ substrate (DEVD-pNA for Drice, and IETD-pNA for Dronc) was added and incubated at $37^{\circ} \mathrm{C}$ for $1.5 \mathrm{~h}$. The reaction was quantified at $405 \mathrm{~nm}$.

\section{Dopamine content}

Dopamine content was measured as per method described by Schlumpf et al. (1974). Fifty heads of flies from each group were taken in $500 \mu \mathrm{L}$ of $\mathrm{HCl}-$ butanol $(0.85 \mathrm{~mL}$ of $37 \% \mathrm{HCl}$ in 1 litre n-butanol). After homogenization the samples were centrifuged at $2200 \mathrm{~g}$ for $5 \mathrm{~min}$. After collecting the supernatant, $250 \mu \mathrm{L}$ of heptane and $100 \mu \mathrm{L}$ of $0.1 \mathrm{M} \mathrm{HCl}$ were added. The samples were vortexed and centrifuged at $2200 \mathrm{~g}$ for $5 \mathrm{~min}$. The upper organic phase was discarded and the lower aqueous phase was kept for dopamine assay. To $100 \mu \mathrm{L}$ of aqueous phase, $50 \mu \mathrm{L} 0.4 \mathrm{M} \mathrm{HCl}, 100 \mu \mathrm{L}$ of sodium acetate buffer ( $\mathrm{pH}$ 6.9), $100 \mu \mathrm{L}$ of iodine solution was added and kept for two min. The reaction was stopped by adding of $100 \mu \mathrm{L}$ of sodium sulphite solution. After two min, $100 \mu \mathrm{L}$ of acetic acid $(10 \mathrm{M})$ was added and then the mixture was heated at $100^{\circ} \mathrm{C}$ for $6 \mathrm{~min}$. The OD was taken at $375 \mathrm{~nm}$ after cooling the samples at room temperature.

\section{Immunohistochemistry}

The fly heads were isolated and paraffin sections were prepared according to the procedure described by Palladino et al. (2000). The sections were deparaffinized and rehydrated. The slides were blocked in $8 \%$ Bovine Serum Albumin (BSA) for $2.5 \mathrm{hr}$. Then the slides were washed with phosphate buffer saline ( $\mathrm{pH}$ 7.2) containing 2\% BSA for 5 minutes. After washing the slides were incubated with primary antibody (anti-tyrosine hydroxylase, Merck) in a humidified chamber for $12 \mathrm{hr}$ at $4{ }^{\circ} \mathrm{C}$. The slides were then washed with PBS containing $2 \%$ BSA for 5 min and incubated with secondary antibody (Goat anti-Rabbit alkaline phosphatase, Santacruz, Biotechnology, USA) at room temperature for $2 \mathrm{~h}$. The final wash was given by PBS containing $2 \%$ BSA for $5 \mathrm{~min}$. BCIP-NBT was used as a chromogenic substrate 
which interacts with secondary antibody to produce blue coloured product. The slides were then mounted in DPX and observed under the microscope.

\section{Statistical analysis}

The statistical analysis was done by performing oneway ANOVA post hoc test using SPSS Ver. 16.

\section{RESULTS}

The result obtained for superoxide anion scavenging activity is shown in Figure 1S. A clear dose dependent significant increase in the superoxide anion scavenging activity of luteolin was observed at 25, 50, 75 and $100 \mu \mathrm{M}$ compared to control. The results obtained for free radical scavenging also showed similar results. A clear dose dependent significant increase in the free radical scavenging activity of luteolin was observed at 25, 50, 75 and $100 \mu \mathrm{M}$ compared to control (Figure 2S). The results obtained for the average activity pattern are shown in Figure (3S-13S). The activity of flies was recorded for $287 \mathrm{hrs}$ and then with the help of software programme was present in the form of average activity pattern and chi-square periodogram. The PD flies showed a decrease in the average activity (Figure 4S) compared to control flies (Figure 3S) which is evident by the chi-square periodogram. The numbers of peaks are more near the midline. The exposure of PD flies to 25, 50, 75 and $100 \mu \mathrm{M}$ of luteolin showed a dose dependent delay in the loss of activity as is evident from chi-square periodogram (Figure $5 \mathrm{~S}-8 \mathrm{~S}$ ). The control flies showed no change in the activity when exposed to 25, 50, 75 and $100 \mu \mathrm{M}$ of luteolin (Figure 9S-12S). The PD flies exposed to $10^{-3} \mathrm{M}$ of dopamine also showed a delay in the loss of activity compared to unexposed PD flies (Figure 13S).

The results obtained for the climbing ability of PD flies showed a significant 4.5 fold of decrease compared to control flies (Figure 1; $<<0.05$ ). The exposure of PD flies to $25,50,75$ and $100 \mu \mathrm{M}$ of luteolin showed a dose dependent significant delay in the loss of climbing ability of $1.52,1.85,2.19$ and 2.67 folds compared to the PD flies (Figure $1 ; \mathrm{p}<0.05$ ). The PD flies exposed to $10^{-3} \mathrm{M}$ of dopamine showed a 3.04 fold significant delay in the loss of climbing ability compared to the PD flies (Figure 1; $\mathrm{p}<0.05)$. The GSH content of PD flies showed a significant decrease of 1.98 fold compared to the control flies (Figure 2; $\mathrm{p}<0.05)$. The PD flies exposed to 25, 50, 75 and $100 \mu \mathrm{M}$ of luteolin showed a dose dependent 1.10, 1.31, 1.48 and 1.64 folds of significant increase in the GSH content compared to unexposed PD flies (Figure 2; $\mathrm{p}<0.05$ ). The exposure of PD flies to $10^{-3} \mathrm{M}$ of dopamine showed a 1.32 fold of significant increase in the GSH content compared to PD flies (Figure 2; $<<0.05$ ). PD flies showed a 2.53 fold of increase in the GST activity compared to control flies (Figure 3; $\mathrm{p}<0.05$ ). The PD flies exposed to 25, 50, 75 and $100 \mu \mathrm{M}$ of luteolin showed a $1.11,1.19,1.25$ and 1.45 folds of significant decrease in the GST activity compared to unexposed PD flies (Figure 3; $<<0.05$ ). The PD flies exposed to $10^{-3} \mathrm{M}$ of dopamine showed a 1.67 fold of significant decrease in the GST activity compared to unexposed PD flies (Figure 3; $<<0.05$ ). The PD flies showed a 5.16 fold significant increase in LPO compared to control flies (Figure 4; $<<0.05$ ). The exposure of PD flies to $25,50,75$ and $100 \mu \mathrm{M}$ of luteolin showed a dose dependent $1.21,1.47,1.77$ and 2.13 folds of significant decrease respectively in the LPO (Figure 4; $<<0.05$ ). The PD flies exposed to $10^{-3} \mathrm{M}$ of dopamine showed a 1.93 fold of significant decrease in LPO compared to unexposed PD flies (Figure 4; $<<0.05$ ). The PD flies showed 3.81 fold of significant increase in PC content compared to control flies (Figure 5; $\mathrm{p}<0.05$ ). The PD flies exposed to 25, 50, 75 and $100 \mu \mathrm{M}$ of luteolin showed a dose dependent significant decrease of 1.16, 1.40, 1.61 and 2.1 folds respectively compared to unexposed PD flies (Figure 5; $<<0.05$ ). The PD flies exposed to $10^{-3} \mathrm{M}$ of dopamine showed a significant decrease of 2.0 fold in the PC content compared to unexposed PD flies (Figure 5; $\mathrm{p}<0.05$ ). The PD flies showed a 4.33 fold significant increase in the activity of caspase-9 compared to control flies (Figure $6 ; \mathrm{p}<0.05$ ). The PD flies exposed to 25, 50, 75 and $100 \mu \mathrm{M}$ of luteolin showed a dose dependent significant decrease of 1.3, 1.5, 1.95 and 2.29 folds respectively compared to unexposed PD flies (Figure 6; $\mathrm{p}<0.05$ ). The PD flies exposed to $10^{-3} \mathrm{M}$ of dopamine showed a 2.43 fold of significant decrease in the caspase-9 compared to unexposed PD flies (Figure 6; $\mathrm{p}<0.05$ ). Similarly, PD flies showed a significant increase of 2.90 fold in the activity of caspase-3, compared to control flies (Figure 7; $<<0.05$ ). The exposure of 25, 50, 75 and $100 \mu \mathrm{M}$ of luteolin showed a significant decrease of $1.23,1.39,1.60$ and 1.88 folds respectively compared to unexposed PD flies (Figure 7; $<0.05$ ). The exposure of PD flies to $10^{-3} \mathrm{M}$ of dopamine showed a 1.88 fold of significant decrease compared to PD flies (Figure 7; $p<0.05)$. A significant decrease of 2.7 fold was observed in the dopamine content in PD flies compared to control flies (Figure 8; $<<0.05$ ). The PD flies exposed to 25, 50, 75 and $100 \mu \mathrm{M}$ of luteolin showed a significant increase of $1.2,1.3,1.5$ and 1.7 folds respectively in the dopamine content (Figure 8; $<<0.05$ ). The PD flies exposed to $10^{-3} \mathrm{M}$ of dopamine showed a significant increase of 1.9 fold in the dopamine content compared to PD flies (Figure 8; 
$\mathrm{p}<0.05)$. The results obtained for immunohistochemistry are depicted in Figure 9(A-C). The less activity of tyrosine hydroxylase was observed in PD flies (Figure 9A) compared to control flies (Figure 9B). The exposure to various doses of luteolin showed a higher activity of tyrosine hydroxylase compared to unexposed PD flies (Figure 9C).

\section{DISCUSSION}

The results of the present study reveal that luteolin not only reduced the oxidative stress but also delayed the loss of climbing ability of the PD model flies. PD

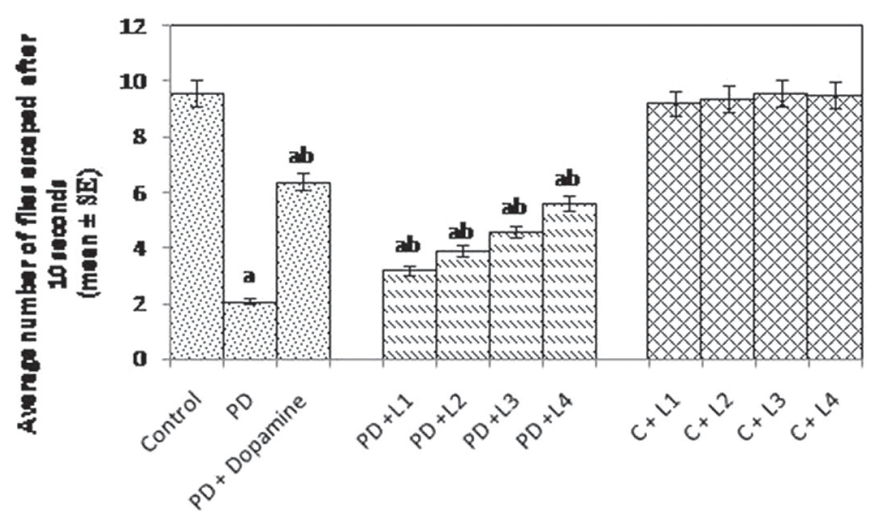

FIGURE 1 - Effect of luteolin on the climbing ability. [L1=25 $\mu \mathrm{M}$; L2 $=50 \mu \mathrm{M}$; L3 $=75 \mu \mathrm{M}$; L4=100 $\mu \mathrm{M}$; PD = PD flies; Dopamine $=10-3 \mathrm{M}]$. The flies were allowed to feed on the diet supplemented with luteolin for 24 days and then assayed for climbing ability. The values are the mean of 5 assays. [a - significant at $\mathrm{p}<0.05$ compared to control; $\mathrm{b}$ - significant at $\mathrm{p}<0.05$ compared to $P D$ flies].

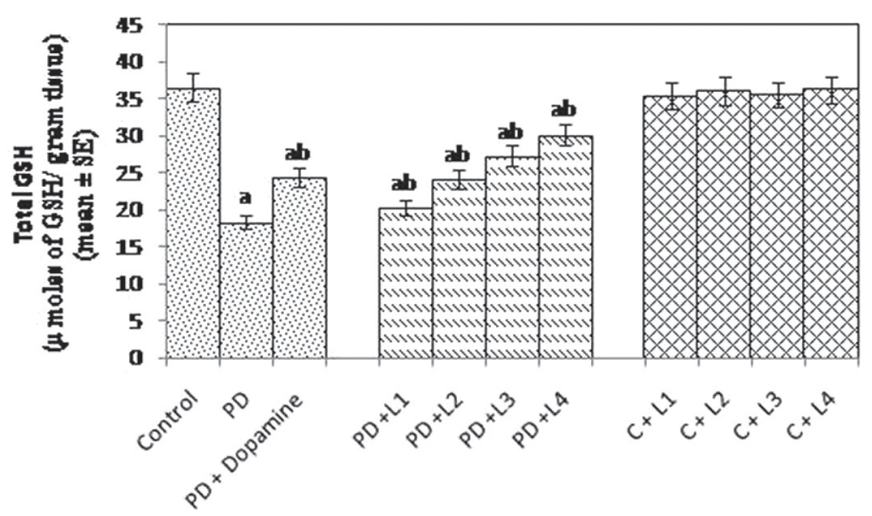

FIGURE 2 - Effect of luteolin on the glutathione (GSH) content in the brains of flies. [L1=25 $\mu \mathrm{M} ; \mathrm{L} 2=50 \mu \mathrm{M} ; \mathrm{L} 3=75 \mu \mathrm{M}$; $\mathrm{L} 4=100 \mu \mathrm{M} ; \mathrm{PD}=\mathrm{PD}$ flies; Dopamine=10-3 M]. The flies were allowed to feed on the diet supplemented with luteolin for 24 days and then assayed for GSH content. The values are the mean of 5 assays. [a - significant at $\mathrm{p}<0.05$ compared to control; $\mathrm{b}$ - significant at $\mathrm{p}<0.05$ compared to PD flies].

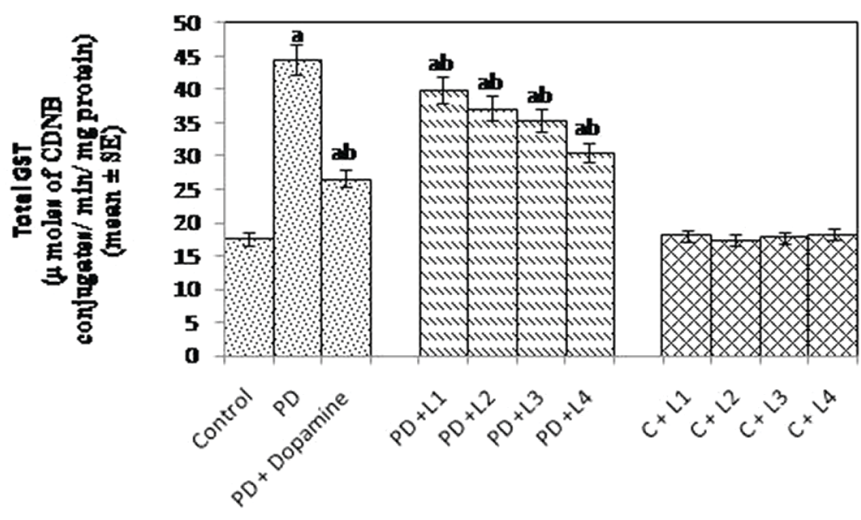

FIGURE 3 - Effect of luteolin on the glutathione- $S$-transferase (GST) activity in the brains of flies. [L1 $=25 \mu \mathrm{M} ; \mathrm{L} 2=50 \mu \mathrm{M}$; L3 $=75 \mu \mathrm{M} ; \mathrm{L} 4=100 \mu \mathrm{M} ; \mathrm{PD}=\mathrm{PD}$ flies; Dopamine=10-3 M]. The flies were allowed to feed on the diet supplemented with luteolin for 24 days and then assayed for GST activity. The values are the mean of 5 assays. [a - significant at $\mathrm{p}<0.05$ compared to control; $\mathrm{b}$ - significant at $\mathrm{p}<0.05$ compared to PD flies].

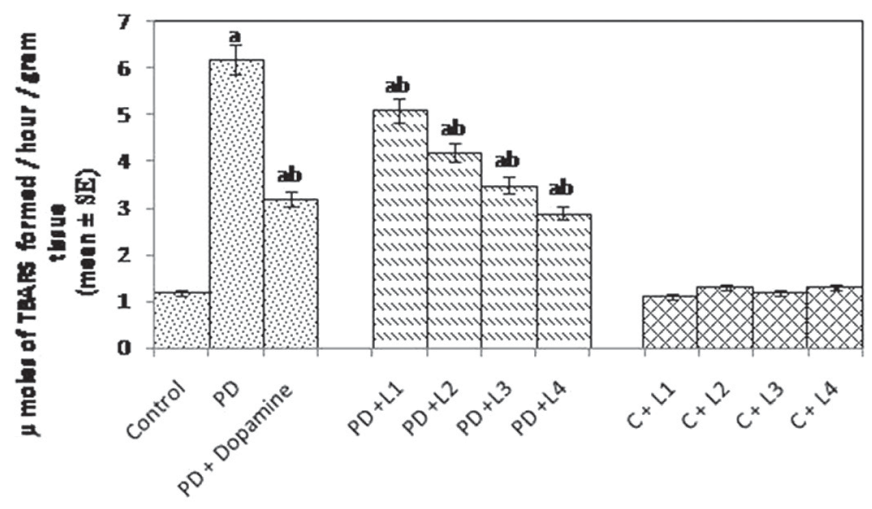

FIGURE 4 - Effect of luteolin on the lipid peroxidation in the brains of flies. $[\mathrm{L} 1=25 \mu \mathrm{M} ; \mathrm{L} 2=50 \mu \mathrm{M} ; \mathrm{L} 3=75 \mu \mathrm{M}$; $\mathrm{L} 4=100 \mu \mathrm{M} ; \mathrm{PD}=\mathrm{PD}$ flies; Dopamine $\left.=10^{-3} \mathrm{M}\right]$. The flies were allowed to feed on the diet supplemented with luteolin for 24 days and then assayed for lipid peroxidation. The values are the mean of 5 assays. [a - significant at $p<0.05$ compared to control; $b$ - significant at $p<0.05$ compared to PD flies].

flies exposed to luteolin also exhibit delay in the loss of climbing ability in a dose dependent manner. The results obtained for activity pattern also suggest that the exposure of PD flies to luteolin showed a dose dependent delay in the loss of activity. There are evidences which supports that dietary derived flavonoids have the potential to improve human memory and neuro-cognitive performance via their ability to protect vulnerable neurons, enhancing neuronal function and stimulate the neuronal regeneration (Spencer, 2008). Luteolin has been reported to improved cognitive impairments in rats and mice (Liu et al., 2013; Jang, Dilger, Johnson, 2010; Xu et al., 2010). 


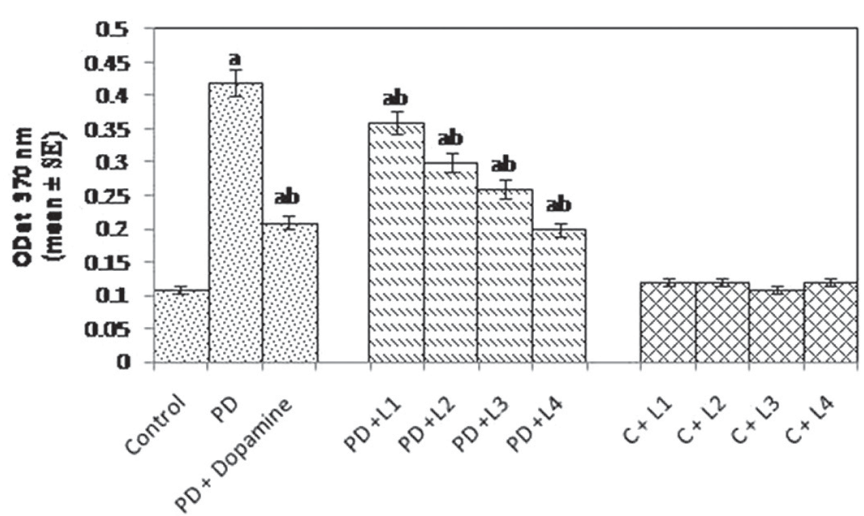

FIGURE 5 - Effect of luteolin on the protein carbonyl content measured in the brains of flies. [L1 $=25 \mu \mathrm{M} ; \mathrm{L} 2=50 \mu \mathrm{M} ; \mathrm{L} 3=$ $75 \mu \mathrm{M}$; L4= $100 \mu \mathrm{M}$; PD = PD flies; Dopamine=10-3 M]. The flies were allowed to feed on the diet supplemented with luteolin for 24 days and then assayed for lipid peroxidation. The values are the mean of 5 assays. [a - significant at $\mathrm{p}<0.05$ compared to control; $b$ - significant at $p<0.05$ compared to PD flies].

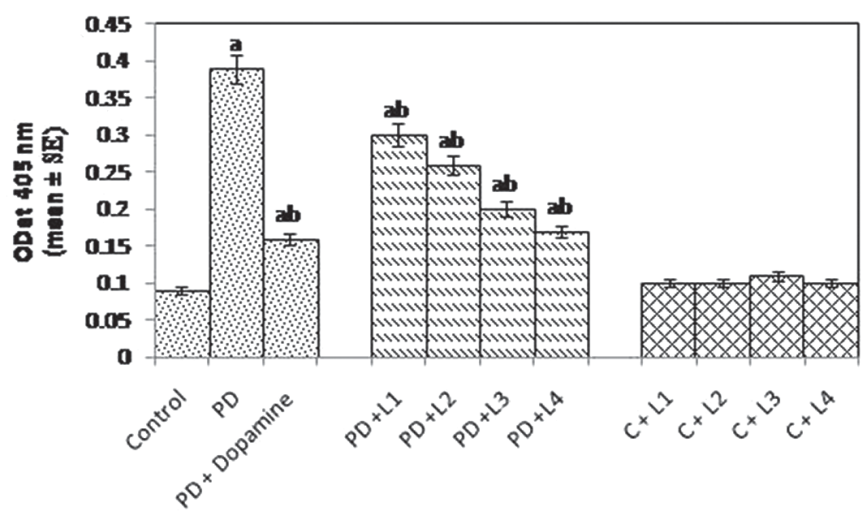

FIGURE 6 - Effect of luteolin on caspase-9 activity in the brains of flies. [L1= $25 \mu \mathrm{M}$; L2 $=50 \mu \mathrm{M} ; \mathrm{L} 3=75 \mu \mathrm{M}$; L4= $100 \mu \mathrm{M}$; $\mathrm{PD}=$ PD flies; Dopamine=10-3 M]. The flies were allowed to feed on the diet supplemented with luteolin for 24 days and then assayed for caspase- 9 activity. The values are the mean of 5 assays. [a - significant at $p<0.05$ compared to control; $\mathrm{b}$ - significant at $\mathrm{p}<0.05$ compared to PD flies].

Oxidative stress is the key component of the pathology of neurodegenerative disorders (Aruoma, Bahorun, Jen, 2003). During the past several years there has been a tremendous progress in the understanding the causative factors for various neurodegenerative disorders but there have been no therapies available that benefits patient suffering from these diseases (Solanki et al., 2015). It is well accepted that the accumulation of intracellular damage by ROS might orchestrate the progressive loss of control over biological homeostasis (Cencioni et al., 2013).

GSH is a tripeptide present in the majority of cells, is responsible for hydrophilic xenobiotics conjugation

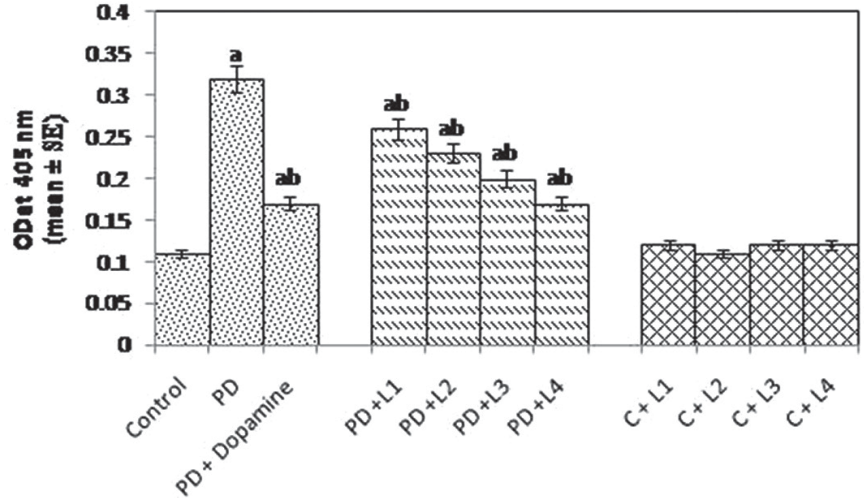

FIGURE 7 - Effect of luteolin on caspase-3 activity in the brains of flies. [L1= $25 \mu \mathrm{M} ; \mathrm{L} 2=50 \mu \mathrm{M} ; \mathrm{L} 3=75 \mu \mathrm{M}$; L4= $100 \mu \mathrm{M}$; $\mathrm{PD}=$ PD flies; Dopamine $=10-3 \mathrm{M}]$. The flies were allowed to feed on the diet supplemented with luteolin for 24 days and then assayed for caspase- 3 activity. The values are the mean of 5 assays. [a - significant at $p<0.05$ compared to control; $b$ - significant at $p<0.05$ compared to PD flies].

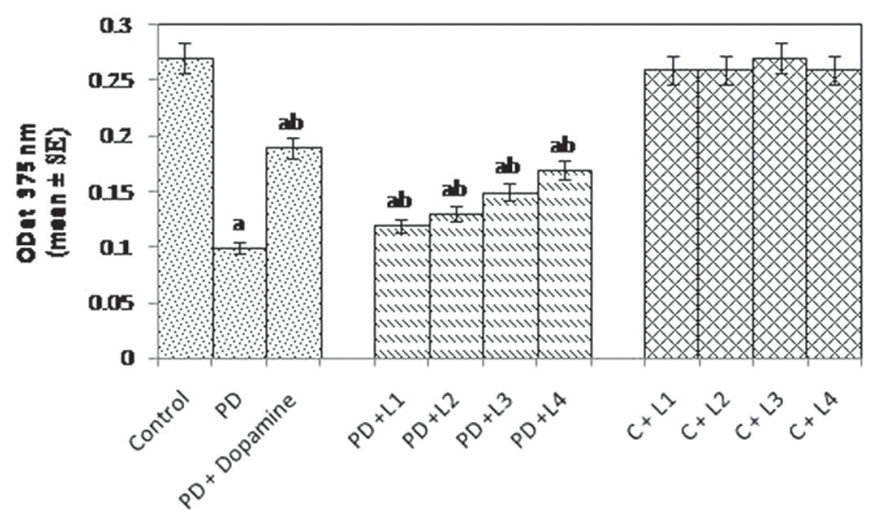

FIGURE 8 - Effect of luteolin on dopamine content measured in the brains of flies. [L1 $=25 \mu \mathrm{M} ; \mathrm{L} 2=50 \mu \mathrm{M} ; \mathrm{L} 3=75 \mu \mathrm{M}$; L4= $100 \mu \mathrm{M} ; \mathrm{PD}=$ PD flies; Dopamine=10-3 M]. The flies were allowed to feed on the diet supplemented with luteolin for 24 days and then assayed for dopamine content. The values are the mean of 5 assays. [a - significant at $p<0.05$ compared to control; $b$ - significant at $p<0.05$ compared to PD flies].

sulphydryl group of glutathione is essential for its antioxidant activity against the ROS in cells (Durgo et al., 2007). GSH is one of the essential compounds for maintaining cell integrity against ROS and as being non enzymatic free radical scavenger, it participates in the detoxification of ROS and reduces $\mathrm{H}_{2} \mathrm{O}_{2}$ (Waseem, Parvez, 2013). A decrease in the GSH content has been reported in PD patients due to the neuronal loss. This decrease in GSH would reduce the capacity of the neurons to detoxify not only hydrogen peroxide but also lipid hydroperoxides and increase the risk of free radical formation and lipid peroxidation (Sofic et al., 1992). There are evidences that some flavonoids can enhance the intracellular basal level 


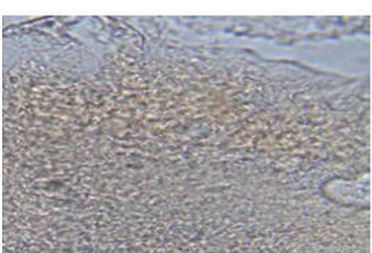

A

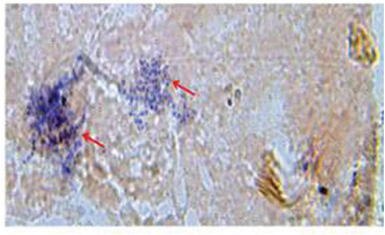

$\mathbf{B}$

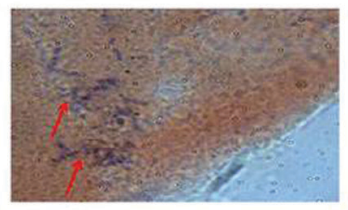

C

FIGURE 9 - Immunohistochemistry performed on the brain sections using anti-tyrosine hydroxylase (primary antibody) and alkaline phosphatase (secondary antibody). BCIP-NBT solution was used as a substrate (100X) [A-PD fly; B-Control; C-PD fly exposed to $100 \mu \mathrm{M}$ of luteolin].

of GSH, thereby promoting the tolerance against free radicals (Cipak et al., 2003). The exposure of luteolin to PD flies showed a dose dependent increase in the GSH content.

Free radicals may also attack unsaturated lipids in a cell, resulting in the chain reaction leading to the breakdown products such as malondialdehyde (MDA). The measurement of MDA concentration is a common method for the determination of LPO. The exposure of luteolin to the PD flies showed a dose dependent decrease in the LPO. GST family of genes has been implicated in multiple neurodegenerative disorders (Allen et al., 2012). The altered level or functions of GST has been associated with the oxidative stress in a way that contributes the progression of the disease (Allen et al., 2012). In our study the PD flies were associated with an increased activity of GST. The exposure of luteolin to PD flies showed a dose dependent decrease in the activity of GST. The increase in the GST activity has also been reported to rescue the dopaminergic neurons in Drosophila (Whitworth et al., 2005). Protein oxidation has been implicated in the pathogenesis of various human diseases (Dalle-Donne et al., 2013). Oxidative damage to protein modifies its symmetrical arrangements via aggregation, fragmentation and formation of cross linkages in the polypeptide chain which further extends the generation of superoxide radical (Waseem, Parvez, 2013; Chen et al., 2005). In our study the PD flies showed a higher content of PC compared to control flies and the exposure of PD flies to luteolin showed a dose dependent decrease in the PC content. In our study the activity of caspase- 3 and 9 were found to be elevated in the brain of PD flies. The flies exposed to luteolin showed a dose dependent decrease in the activity of caspase 3 and 9. Apoptotic neuronal death plays an important PD (Guo et al., 2013). In number of studies besides showing the antioxidative properties luteolin has shown anti-apoptotic properties (Guo et al., 2013; Zhu et al., 2011; Lin et al., 2010; Kim, Chin, Cho, 2017).

Many plant polyphenolic compounds possess antioxidative as well as other biological activities (Yang et al., 1997). We have estimated the potential of luteolin in scavenging the ROS by performing superoxide anion scavenging and DPPH assay. Both the assays showed that luteolin have a significant potential in scavenging the ROS at the doses used in our present study. The results obtained for the immunostaining for tyrosine hydroxylase also showed the presence of dopaminergic neurons in the PD flies exposed to various doses of luteolin. The results clearly demonstrates that the luteolin effectively provide protection to the neurons by reducing the oxidative stress.

The exposure of luteolin showed a dose dependent increase in the dopamine content in the brains of PD flies. Luteolin showed the protection of dopaminergic neurons by inhibiting the microglial activation and thereby preventing the generation of tumor necrosis factor- $\alpha$, nitric oxide and superoxide (Chen et al., 2008). A decrease in dopamine content is associated with the progressive degeneration of dopaminergic neurons (Rekha et al., 2013). Tyroxine hydroxylase is the rate limiting enzyme for the formation of dopamine. In our present study its expression was used to identify surviving dopaminergic neurons (Jackson-Lewis et al., 1995). Tyroxine hydroxylase immuno-reactivity describes the number of survival neurons. PD patients generally show a decrease in the activity of tyroxine hydroxylase, being more pronounced in the nigrostraital system (Rausch et al., 1988). Considering our results in the present study the localization of tyroxine hydroxylase in PD flies exposed to luteolin further strengthens and supports the protective role of luteolin in the flies expressing human alpha synuclein. Using Drosophila as a study model, one can easily analyze the pharmacological properties of plants/ plant derived components by performing several assays. The pharmacological properties of various natural plant products using Drosophila as a model have been extensively reviewed by Panchal and Tiwari (2017). Our earlier studies using the same study model on flavonoids/ plant extracts (Fatima et al., 2017; Siddique et al., 2016; Siddique, Naz, Jyoti, 2014) have also shown the promising results in reducing the PD symptoms. Hence, it is concluded that the luteolin is potent in reducing the PD symptoms in transgenic Drosophila expressing human alpha synuclein in the neurons. 


\section{CONCLUSION}

It is concluded that luteolin is potent in reducing the PD symptoms in transgenic Drosophila expressing human alpha synuclein in the neurons.

\section{ACKNOWLEDGEMENTS}

We are thankful to the chairman, Department of Zoology, Aligarh Muslim University, Aligarh for providing the laboratory facilities. The Council Science and Technology, Uttar Pradesh is gratefully acknowledge for (CST) Sanctioning the project entitled "Role of kaempherol and luteolin on the neurotoxicity and neurogenerative changes in the brain of Parkinson's disease model transgenic flies" (CST/SERPD/D-296; Dated: 14 May, 2015).

\section{CONFLICT OF INTEREST STATEMENT}

The authors declare that there are no conflicts of interest.

\section{SUPPLEMENTARY FIGURES}

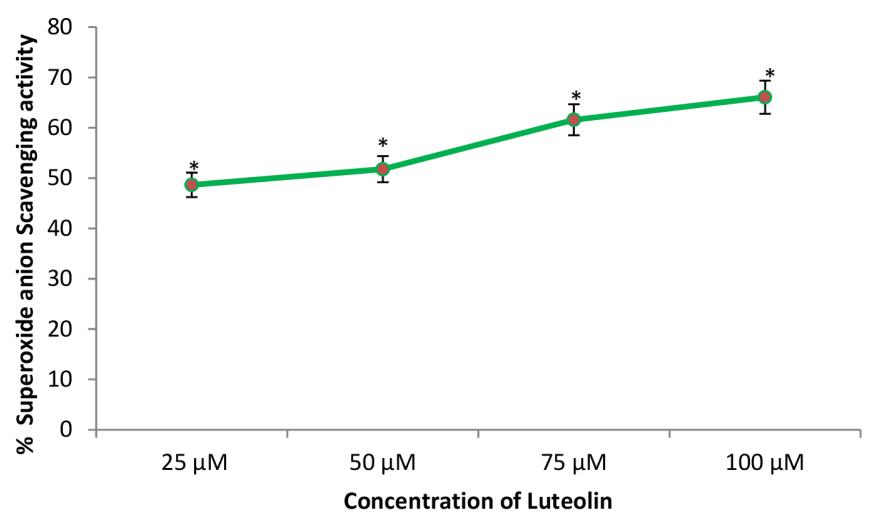

FIGURE $1 S$ - Super oxide anion scavenging activity of luteolin. The values are the mean of five assays [*significant with respect to control, $\mathrm{p}<0.05]$.

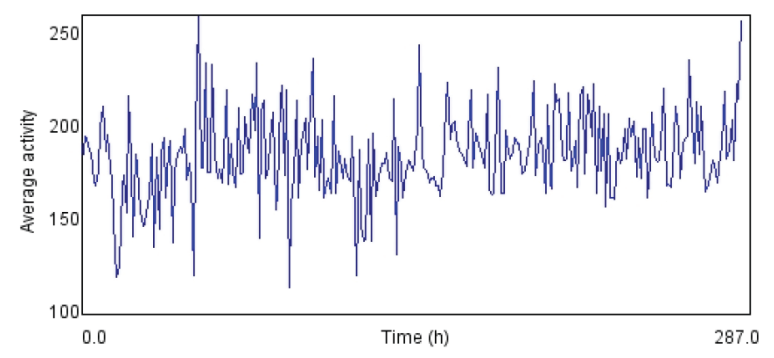

(a)

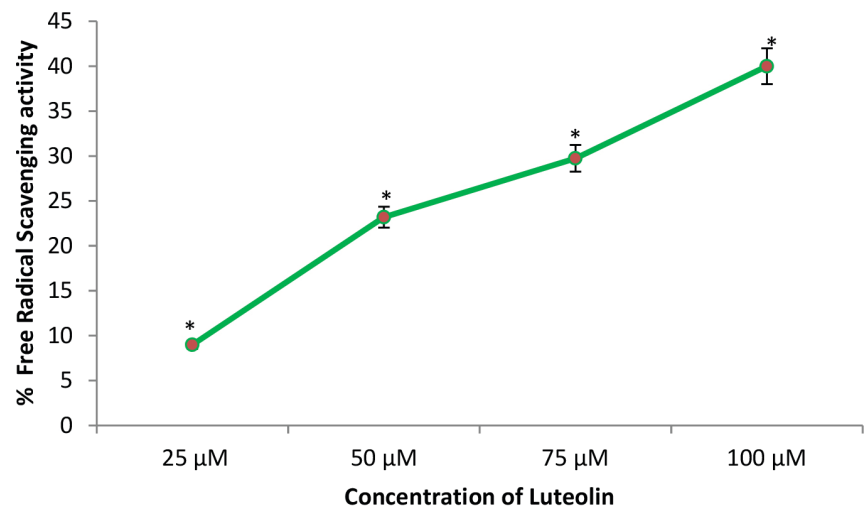

FIGURE 2 S - Free radical scavenging activity of luteolin. The values are the mean of five assays [* ${ }^{*}$ significant with respect to control, $\mathrm{p}<0.05]$.

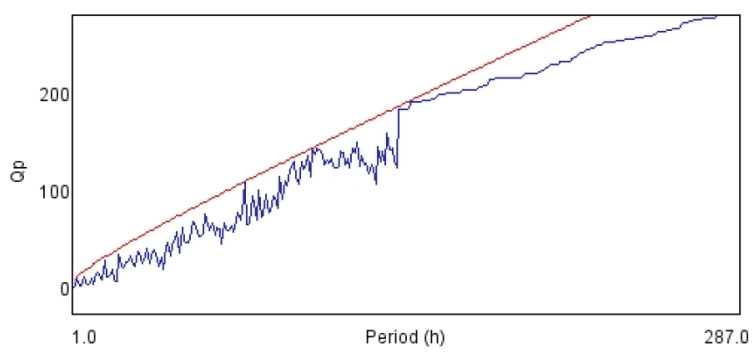

(b)

FIGURE $3 S$ - (a) and (b) shows the average activity pattern and chi-square periodogram respectively for control flies $(\mathrm{N}=20)$. 


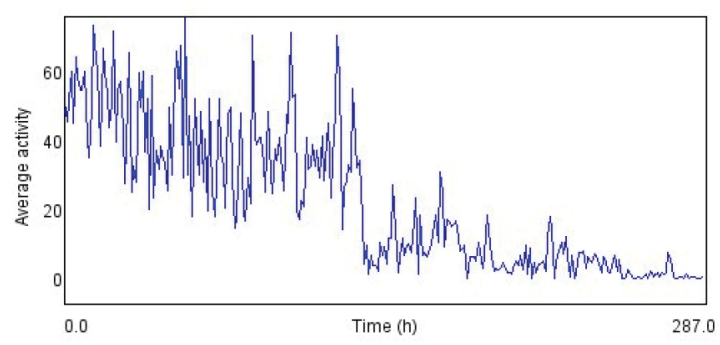

(a)

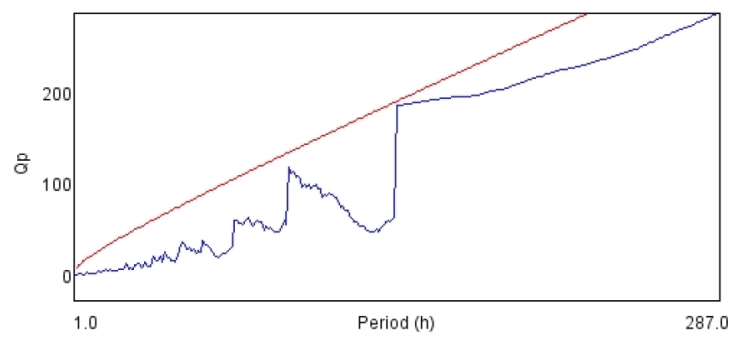

(b)

FIGURE 4S - (a) and (b) shows the average activity pattern and chi-square periodogram respectively for PD flies (N=20).

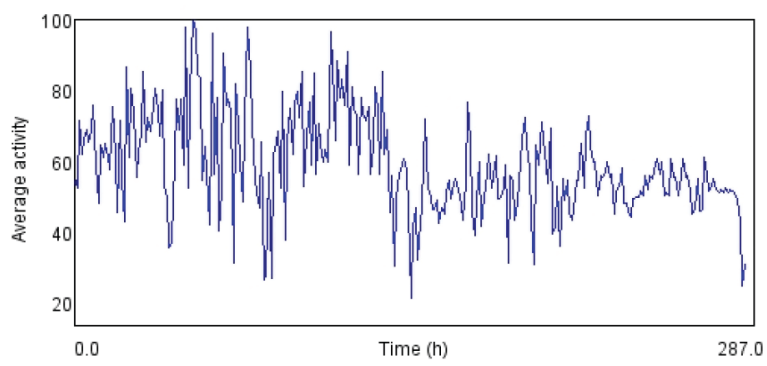

(a)

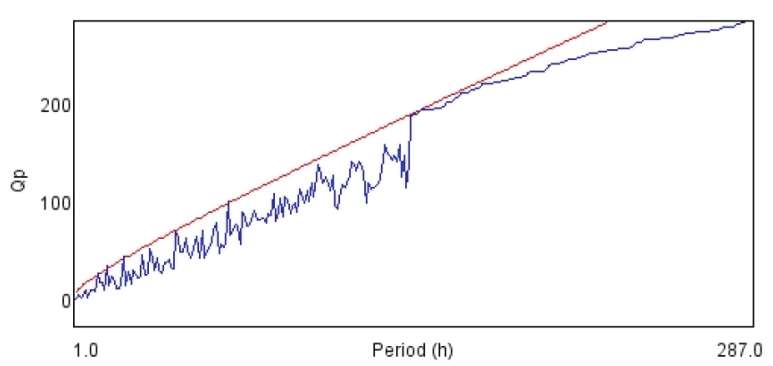

(b)

FIGURE $5 S$ - (a) and (b) shows the average activity pattern and chi-square periodogram respectively for PD flies exposed to luteolin $(25 \mu \mathrm{M})$.

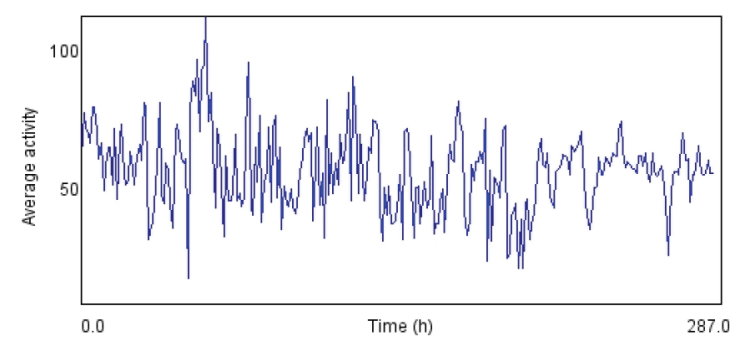

(a)

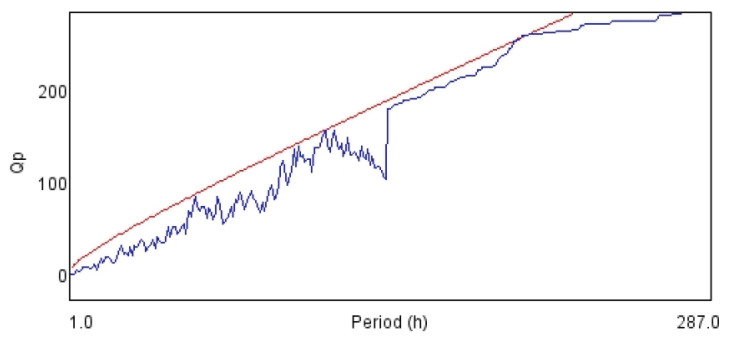

(b)

FIGURE $6 S$ - (a) and (b) shows the average activity pattern and chi-square periodogram respectively for PD flies exposed to luteolin $(50 \mu \mathrm{M})$.

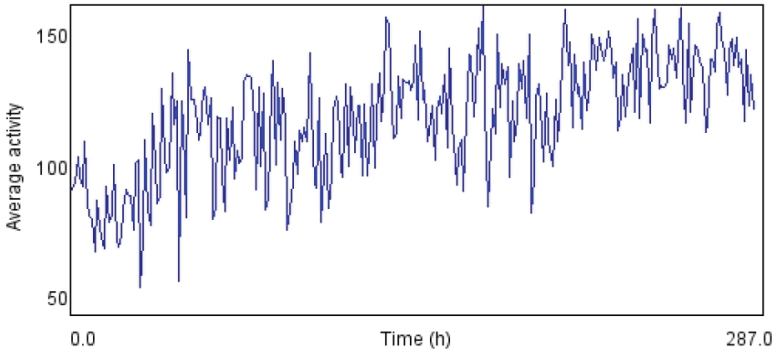

(a)

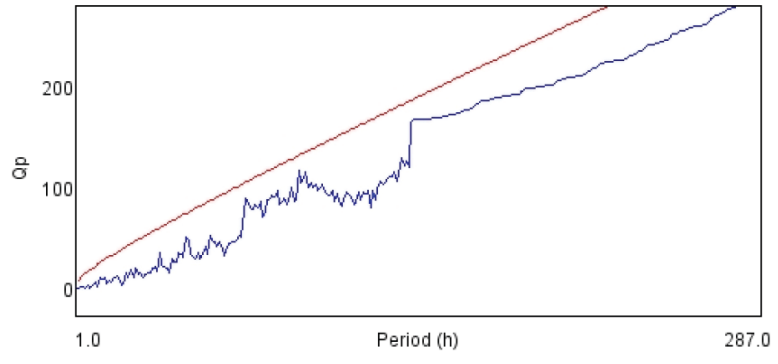

(b)

FIGURE 7S - (a) and (b) shows the average activity pattern and chi-square periodogram respectively for PD flies exposed to luteolin $(75 \mu \mathrm{M})$. 


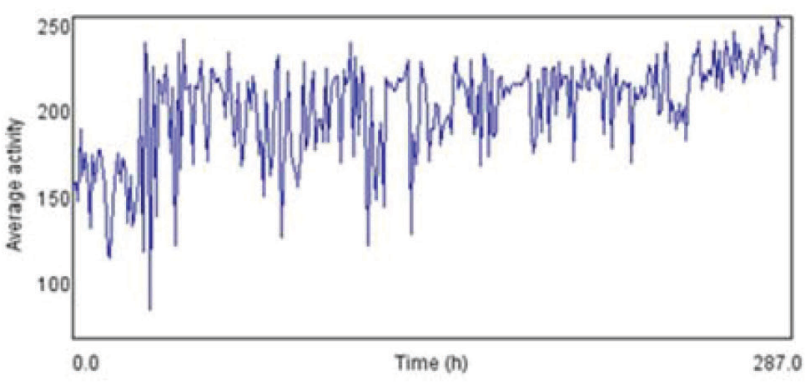

(a)

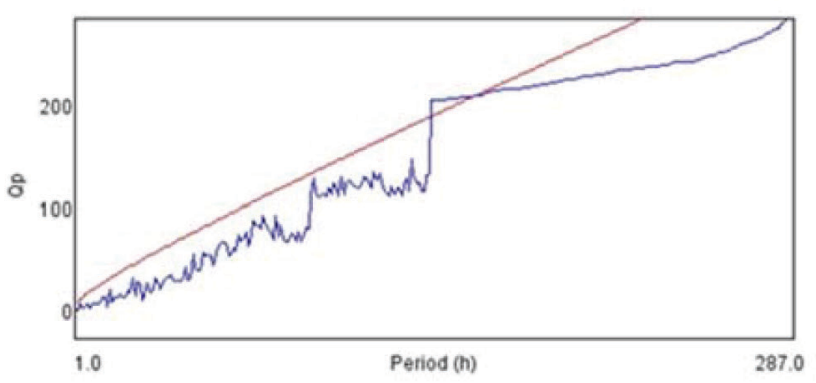

(b)

FIGURE 8S - (a) and (b) shows the average activity pattern and chi-square periodogram respectively for PD flies exposed to luteolin $(100 \mu \mathrm{M})$.

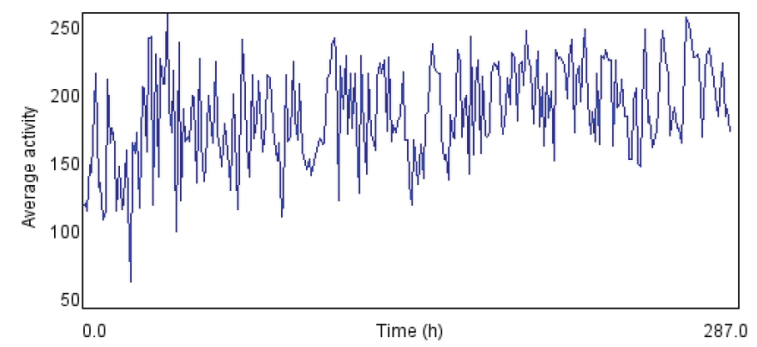

(a)

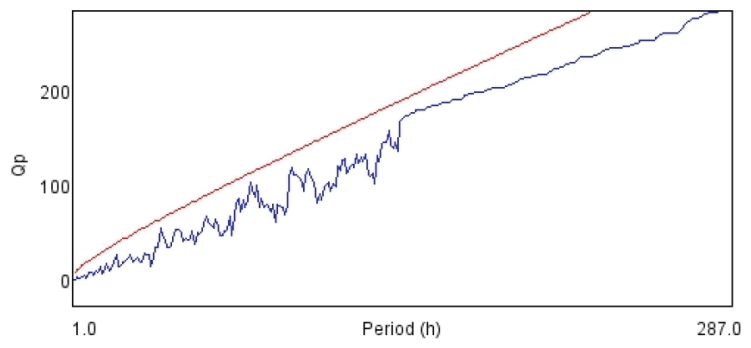

(b)

FIGURE 9S - (a) and (b) shows the average activity pattern and chi-square periodogram respectively for Control flies exposed to luteolin $(25 \mu \mathrm{M})$.

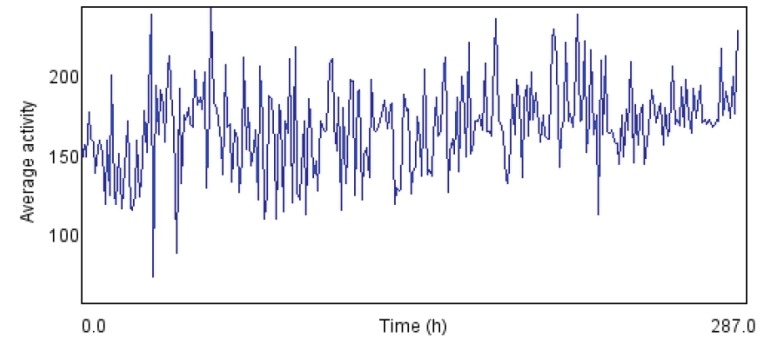

(a)

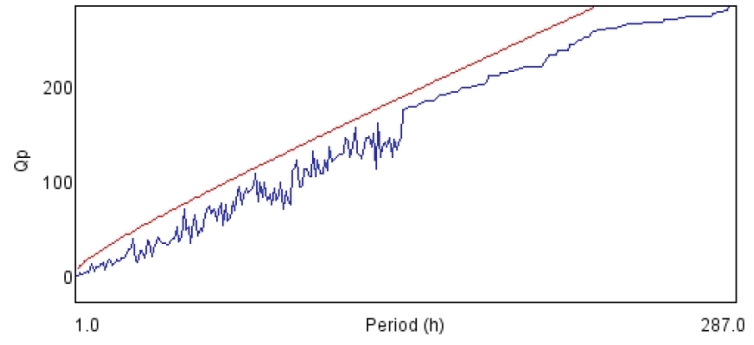

(b)

FIGURE 10S - (a) and (b) shows the average activity pattern and chi-square periodogram respectively for Control flies exposed to luteolin $(50 \mu \mathrm{M})$.

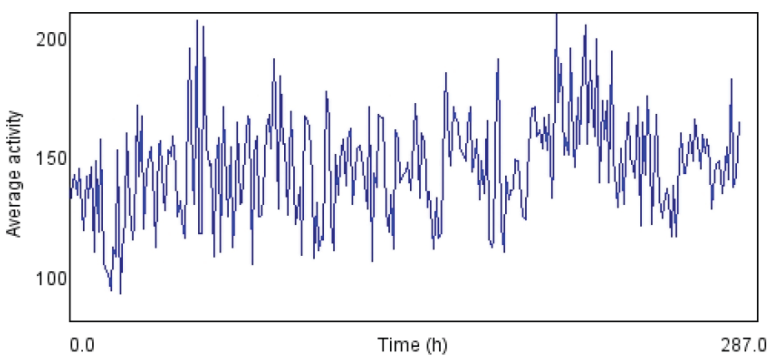

(a)

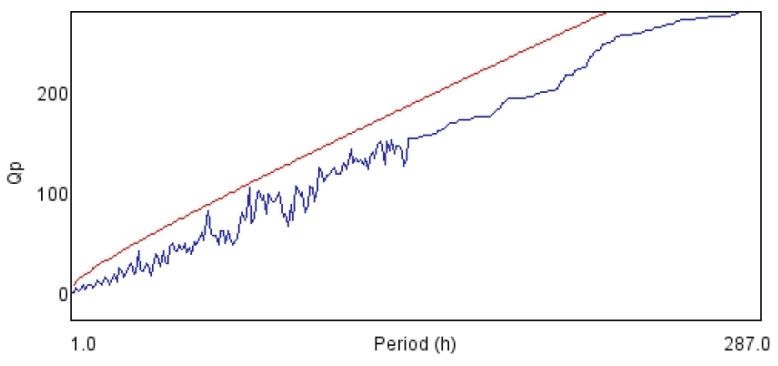

(b)

FIGURE 11S - (a) and (b) shows the average activity pattern and chi-square periodogram respectively for Control flies exposed to luteolin $(75 \mu \mathrm{M})$. 


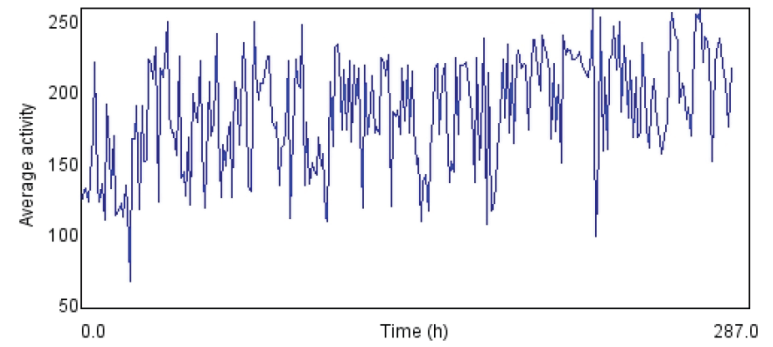

(a)

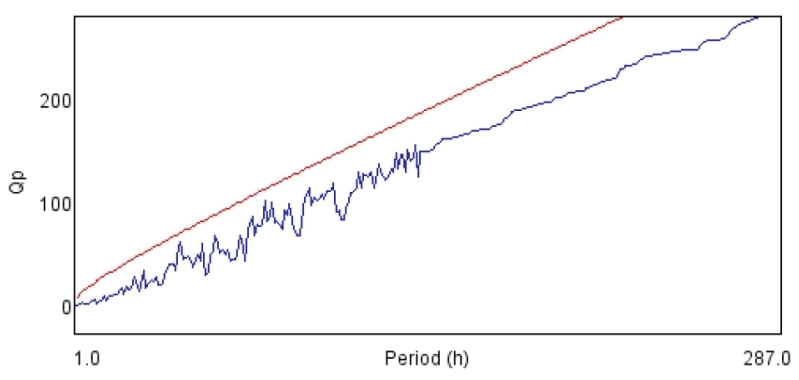

(b)

FIGURE 12S - (a) and (b) shows the average activity pattern and chi-square periodogram respectively for Control flies exposed to luteolin $(100 \mu \mathrm{M})$.

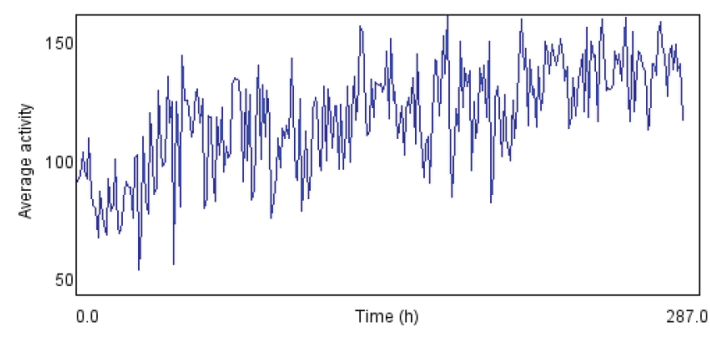

(a)

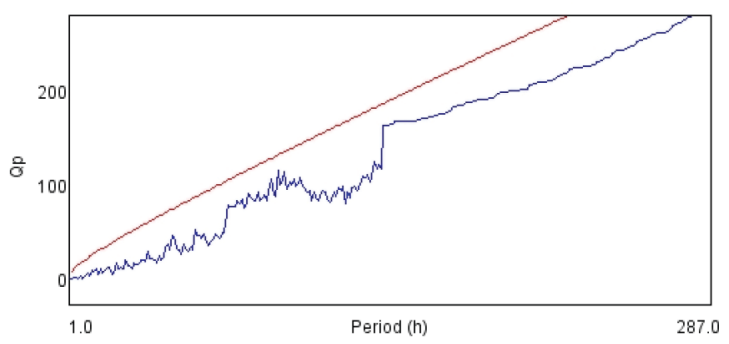

(b)

FIGURE $13 S$ - (a) and (b) shows the average activity pattern and chi-square periodogram respectively for PD flies exposed to dopamine $\left(10^{-3} \mathrm{M}\right)$.

\section{REFERENCES}

Allen M, Zou F, Chai HS, Younkin CS, Miles R, Nair AA, Nguyen T. Glutathione S-transferase omega genes in Alzheimer and Parkinson disease risk, age at diagnosis and brain gene expression: an association study with mechanistic implications. Mol Neurodegener. 2012;7(1):13.

Aruoma OI, Bahorun T, Jen LS. Neuroprotection by bioactive components in medicinal and food plant extracts. Mut Res. 2003;544(2):203-215.

Auluck PK, Chan HE, Trojanowski JQ, Lee VMY, Bonini NM. Chaperone suppression of $\alpha$-synuclein toxicity in a Drosophila model for Parkinson's disease. Science. 2002;295(5556):865-868.

Behl C, Holsboer F. Oxidative stress in the pathogenesis of Alzheimer's disease and antioxidant neuroprotection. Fortschr Neurol Psychiatr. 1998;66(3):113-121.

Cencioni C, Spallotta F, Martelli F, Valente S, Mai A, Zeiher AM, Gaetano C. Oxidative stress and epigenetic regulation in ageing and age-related diseases. Int J Mol Sci. 2013;14(9):1764317663.
Chen D, Daniel KG, Chen MS, Kuhn DJ, Landis-Piwowar KR, Dou QP. Dietary flavonoids as proteasome inhibitors and apoptosis inducers in human leukemia cells. Biochem Pharmacol. 2005;69(10):1421-1432.

Chen HQ, Jin ZY, Wang XJ, Xu XM, Deng L, Zhao JW. Luteolin protects dopaminergic neurons from inflammation-induced injury through inhibition of microglial activation. Neurosci Lett. 2008;448(2):175-179.

Čipák L, Rauko P, Miadoková E, Čipáková I, Novotný L. Effects of flavonoids on cisplatin-induced apoptosis of HL-60 and L1210 leukemia cells. Leuk Res. 2003;27(1):65-72.

Cookson MR. The biochemistry of Parkinson's disease. Annu Rev Biochem. 2005;74:29-52.

Durgo K, Vuković L, Rusak G, Osmak M, Franekić Čolić J. Effect of flavonoids on glutathione level, lipid peroxidation and cytochrome P450 CYP1A1 expression in human laryngeal carcinoma cell lines. Food Technol Biotechnol. 2007;45(1):6979. 
Dalle-Donne I, Milzani A, Gagliano N, Colombo R, Giustarini D, Rossi R. Molecular mechanisms and potential clinical significance of S-glutathionylation. Antioxid Redox Signal. 2008;10(3):445-474.

Fatima A, Khanam S, Rahul, Jyoti S, Naz F, Ali F, Siddique YH. Protective effect of tangeritin in transgenic Drosophila model of Parkinson's disease. Front Biosci. 2017;9:44.

Feany MB, Bender WW. A Drosophila model of Parkinson's disease. Nature. 2000;404(6776):394-398.

Filomeni G, Graziani I, De Zio D, Dini L, Centonze D, Rotilio G, Ciriolo MR. Neuroprotection of kaempferol by autophagy in models of rotenone-mediated acute toxicity: possible implications for Parkinson's disease. Neurobiol Aging. 2012;33(4):767-785.

Guo DJ, Li F, Yu PHF, Chan SW. Neuroprotective effects of luteolin against apoptosis induced by 6-hydroxydopamine on rat pheochromocytoma PC12 cells. Pharmaceut Biol. 2013;51(2):190-196.

Hawkins CL, Morgan PE, Davies MJ. Quantification of protein modification by oxidants. Free Radic Biol Med. 2009;46(8):965988.

Habig WH, Pabst MJ, Fleischner G, Gatmaitan Z, Arias IM, Jakoby WB. The identity of glutathione S-transferase B with ligand in, a major binding protein of liver. Proc Natl Acad Sci. 1974;71(10):3879-3882.

Jackson-Lewis V, Jakowec M, Burke RE, Przedborski S. Time course and morphology of dopaminergic neuronal death caused by the neurotoxin 1-methyl-4-phenyl-1, 2, 3, 6-tetrahydropyridine. Neurodegeneration. 1995;4(3):257-269.

Jang S, Dilger RN, Johnson RW. Luteolin inhibits microglia and alters hippocampal-dependent spatial working memory in aged mice. J Nutr. 2010;140(10):1892-1898.

Jenner P, Olanow CW. The pathogenesis of cell death in Parkinson's disease. Neurology. 2006;66(10 Suppl 4):S24-S36.

Jollow DJ, Mitchell JR, Zampaglione NA, Gillette JR. Bromobenzene-induced liver necrosis. Protective role of glutathione and evidence for 3,4-bromobenzene oxide as the hepatotoxic metabolite. Pharmacology. 1974;11(3):151-169.
Kim S, Chin YW, Cho J. Protection of cultured cortical neurons by luteolin against oxidative damage through inhibition of apoptosis and induction of heme oxygenase-1. Biol Pharm Bull. 2017;40(3):256-265.

Lin CW, Wu MJ, Liu IYC, Su JD, Yen JH. Neurotrophic and cytoprotective action of luteolin in PC12 cells through ERKdependent induction of Nrf2-driven HO-1 expression. J Agric Food Chem. 2010;58(7):4477-4486.

Liu Y, Gou LS, Tian X, Fu XB, Ling X, Sun LY, Yin XX. Protective effects of luteolin on cognitive impairments induced by psychological stress in mice. Exp Biol Med. 2013;238(4):418-425.

Meng X, Munishkina LA, Fink AL, Uversky VN. Effects of various flavonoids on the-synuclein fibrillation process. Parkinson's Dis. 2010;2010:650794.

Marsh JL, Thompson LM. Drosophila in the study of neurodegenerative disease. Neuron. 2006;52(1):169-178.

Ohkawa H, Nobuko O, Yagi K. Reaction of linoleic acid hydroperoxide with thiobarbituric acid. J Lipid Res. 1978;19(8):1053-1057.

Panchal K, Tiwari AK. Drosophila melanogaster "a potential model organism" for identification of pharmacological properties of plants/plant-derived components. Biomed Pharmacother. 2017;89:1331-1345.

Palladino MJ, Keegan LP, O'Connell MA, Reenan RA. A-to-I pre mRNA editing in Drosophila is primarily involved in adult nervous system function and integrity. Cell. 2000;102(4):437-49.

Pendleton RG, Parvez F, Sayed M, Hillman R. Effects of pharmacologicalagents upon a transgenic model of Parkinson's disease in Drosophila melanogaster. J Pharmacol Exp Ther. 2002;300(1):91-96.

Rausch WD, Hirata Y, Nagatsu T, Riederer P, Jellinger K. Tyrosine hydroxylase activity in caudate nucleus from Parkinson's disease: effects of iron and phosphorylating agents. J Neurochem. 1988;50(1):202-208.

Rekha KR, Selvakumar GP, Santha K, Sivakamasundari RI. Geraniol attenuates $\alpha$-synuclein expression and neuromuscular impairment through increase dopamine content in MPTP intoxicated mice by dose dependent manner. Biochem Biophys Res Commun. 2013;440(4):664-670. 
Rasato E, Kyriacou CP. Analysis of locomotor activity rhythms in Drosophila. Nat Protoc. 2006;1(2):559-568.

Shaltiel-Karyo R, Davidi D, Menuchin Y, Frenkel-Pinter M, Marcus-Kalish M, Ringo J, Segal D. A novel, sensitive assay for behavioral defects in Parkinson's disease model Drosophila. Parkinson's Dis. 2012;2012:697564.

Siddique YH, Khan W, Fatima A, Jyoti S, Khanam S, Naz F, Naqvi AH. Effect of bromocriptine alginate nanocomposite (BANC) on a transgenic Drosophila model of Parkinson's disease. Dis Model Mech. 2016;9(1):63-68.

Siddique YH, Ara G, Jyoti S, Afzal M. Protective effect of curcumin in transgenic Drosophila melanogaster model of Parkinson's disease. Altern Med Stud. 2012;2(1):7-9.

Siddique YH, Naz F, Jyoti S. Effect of curcumin on lifespan, activity pattern, oxidative stress, and apoptosis in the brains of transgenic Drosophila model of Parkinson's disease. BioMed Res Int. 2014;2014:606928.

Sofic E, Lange KW, Jellinger K, Riederer P. Reduced and oxidized glutathione in the substantia nigra of patients with Parkinson's disease. Neurosci Lett. 1992;142(2):128-130.

Sghaier MB, Bhouri W, Neffati A, Boubaker J, Skandrani I, Bouhlel I, Ghedira K. Chemical investigation of different crude extracts from Teucrium ramosissimum leaves. Correlation with their antigenotoxic and antioxidant properties. Food Chem Toxicol. 2011;49(1):191-201.

Schlumpf M, Lichtensteiger W, Langemann H, Waser PG, Hefti F. A fluorometric micromethod forthe simultaneous determination of serotonin, noradrenaline and dopamine in milligram amounts of brain tissue. Biochem Pharmacol. 1974;23(17):2437-2446.

Solanki I, Parihar P, Mansuri ML, Parihar MS. Flavonoidbased therapies in the early management of neurodegenerative diseases. Adv Nutr. 2015;6(1):64-72.

Spencer JP. Food for thought: the role of dietary flavonoids in enhancing human memory, learning and neuro-cognitive performance. Proc Nutr Soc. 2008;67(02):238-252.
Singh N, Rajini PS. Free radical scavenging activity of an aqueous extract of potato peel. Food Chem. 2004;85(4):611-616.

Seidl SE, Santiago JA, Bilyk H, Potashkin JA. The emerging role of nutrition in Parkinson's disease. Front Integr Neurosci. 2014;6:36.

Thomas B, Beal FM. Parkinson's disease. Hum Mol Gen. 2007;16:Spec n. 2:R183-R194.

Waseem M, Parvez S. Mitochondrial dysfunction mediated cisplatin induced toxicity: modulatory role of curcumin. Food Chem Toxicol. 2013;53:334-342.

Whitworth AJ, Theodore DA, Greene JC, Beneš H, Wes PD, Pallanck LJ. Increased glutathione S-transferase activity rescues dopaminergic neuron loss in a Drosophila model of Parkinson's disease. Proc Natl Acad Sci. 2005;102(22):8024-8029.

Wongsawatkul O, Prachayasittikul S, Isarankura-Na-Ayudhya C, Satayavivad J, Ruchirawat S, Prachayasittikul V. Vasorelaxant and antioxidant activities of Spilanthes acmella Murr Int J Mol Sci. 2008;9(12):2724-2744.

Xu B, Li XX, He GR, Hu JJ, Mu X, Tian S, Du GH. Luteolin promotes long-term potentiation and improves cognitive functions in chronic cerebral hypoperfused rats. Eur J Pharmacol. 2010;627(1):99-105.

Yang CS, Lee MJ, Chen L, Yang GY. Polyphenols as inhibitors of carcinogenesis. Environ Health Perspect. 1997;105(Supl 4):971-976.

Youdim KA, Spencer JP, Schroeter H, Rice-Evans C. Dietary flavonoids as potential neuroprotectants. Biol Chem. 2002;383(3-4):503-519.

Zhu LH, Bi W, Qi RB, Wang HD, Lu DX. Luteolin inhibits microglial inflammation and improves neuron survival against inflammation. Int J Neurosci. 2011;121(6):329-336.

Received for publication on $23^{\text {rd }}$ November 2017 Accepted for publication on $03^{\text {rd }}$ January 2018 